\title{
Representaciones creadas, verdades falsas, de las personas con discapacidad en la vida comunitaria
}

\section{Created representations, false truths, of people with disabilities}

\author{
Tomás Silva Montealegre ${ }^{a}$
}

\begin{abstract}
Resumen
El departir de los conocedores, y no conocedores, en el campo de la discapacidad resulta serdegraninterés parael conocimientocientífico como para el común; pues lleva a analizar, mirary conocer las formas de entender a una condición y a un actor, es decir discapacidad-persona con discapacidad, dentro de las estructuras sociales y de relaciones humanas que se van tejiendo al paso de la historia. Así pues, el tema de la discapacidad en Trabajo Social se ha venido incrementado en la intervención como en la investigación desde los diversos campos y áreas de la disciplina, permitiendo solidificar la visión social sobre la discapacidad y las personas con discapacidad. Por lo que desde esta disciplina se aborda las representaciones sociales de la discapacidad enmarcándose en el ámbito comunitario, donde se tejen conceptos que consideran la realidad de lo que es la persona con discapacidad. De igual forma estas representaciones además de crear el concepto, también juegan un papel importante en la acción hacia lo que se está conceptualizando, en este caso la comunidad construye lo que es la persona con discapacidad y a la par va generando una acción que puede favorecer o perjudicar el desarrollo de la persona con discapacidad en la vida comunitaria. Ante esto, la investigación aquí expuesta aporta datos que permiten conocer cuáles son las representaciones sociales que se tiene de la discapacidad, aportando elementos teóricos, metodológicos y prácticos desde la mirada del Trabajo Social en el campo de la discapacidad.
\end{abstract}

Palabras clave: discapacidad, comunidad, trabajo social, representación social.

\begin{abstract}
The share of the connoisseurs and not knowledgeable in the field of disabilities proves to be of great interest to the scientific knowledge as to the common; therefore, leads to analyze, look and learn the ways of understanding to a condition and an actor, i.e.: disabilityperson with disabilities, within the social structures and human
\end{abstract}

a Universidad Nacional

Autónoma de México, Escuela Nacional de Trabajo Social, México.

Correspondencia a: ts.tomas@comunidad.unam.mx

Recibido:

15 junio 2018

Aceptado:

5 noviembre 2018

Artículo publicado en acceso abierto bajo la Licencia Creative Commons.

\section{(c) (i)}

Cita:

Silva Montealegre, T. (2018).

Representaciones creadas, verdades falsas, de las personas con discapacidad en la vida comunitaria. Kera Yvoty: reflexiones sobre la cuestión social, 3, 38-53. 
relationships that are woven to step of the history. Thus, the issue of disability in Social Work has been increased in the intervention as in the research from the various fields and areas of the discipline, allowing solidify the social vision on the disability and people with disabilities. So from this discipline addresses the social representations of disability framed in the Community sphere, where are woven concepts that are considered to be the reality of what is the person with disability. Likewise, these representations in addition to creating the concept, also play an important role in the action toward what is being conceptualizing, in this case the community constructs which is the person with a disability and to the couple is generating an action that may favor or hinder the development of the person with disability in community life. Before this, is that the present investigation provides data that allow to know which are the social representations that it has on the disability providing theoretical, methodological and practical from the viewpoint of the Social Work in the field of disability.

Keywords: disability, social work, community, social representation.

\section{Introducción}

Ingresar al soliloquio que se ha venido construyendo en el campo de la discapacidad, se penetra a un universo de argumentos y posturas que se ofertan desde las Ciencias Físico-Matemáticas y las Ingenierías, Ciencias Biológicas, Químicas y de la Salud, Ciencias Sociales, así como desde las Humanidades y Artes.

Por ello que, al incurrir en el estudio del campo de la discapacidad, quien se interese en investigar sobre la discapacidad-persona con discapacidad tendrá que enfrentarse a múltiples caminos teóricos, metodológicos, temáticos e instrumentales, que le permitan responder a la vasta gama de preguntas que se tenga sobre una particularidad de dicho campo y así lograr expresar una nueva ruta o argumento sobre la forma de entender y abordar a la discapacidad y a las personas con discapacidad.

Así que, al adentrase a los caminos de la investigación en discapacidad, conlleva a envestirse no solo como investigador social, sino como un artesano intelectual, pues la creatividad, la experiencia, las notas o apuntes, las constantes vigilancias sobre el plan marcado y la necedad de lograr lo que se ha planteado el investigador, hace que este se transforme en un artesano intelectual.

Es así entonces que, desde esta mirada, quien suscribe, se enviste como aquel artesano/investigador y muestra la pieza que se hace llamar Representaciones creadas, verdades falsas, de la discapacidad en la vida comunitaria.

La materia puesta en el bastidor, ha sido el campo de la discapacidad, un campo que a lo largo de la historia ha mostrado ser un espacio de constante cambio y también de lucha por hacer valer y reconocer a un sujeto social denominado persona con discapacidad, detonando así una apertura de tópicos al hablar e investigar sobre discapacidad-persona con discapacidad. El tópico central que se aborda en el presente texto es la representación social que se posee de la condición de la discapacidad; una condición que se legitima y conceptualiza desde múltiples miradas y voces, siendo legitimada desde la mirada y voz del profesional, sociedad o persona con discapacidad, sin poder llegar a conjuntar las tres miradas y voces.

Así entonces resulta ser atractivo para el artesano/investigador indagar sobre las representacionessocialesdeladiscapacidad, convirtiéndose en una aventura irresistible de mirar dichas representaciones en el espacio comunitario, pues en este espacio dinámico la discapacidad no se excluye de representaciones que se van tejiendo de conceptos y prácticas sociales de lo que pareciera ser la "realidad-real" de la discapacidad, es así que la investigación 
tuvo como objetivo analizar la actitud e informaciónen las representacionessociales de la discapacidad en la vida comunitaria de la colonia Gustavo Díaz Ordaz en el municipio de Ecatepec de Morelos, Estado de México, llevando así a responder las sientes interrogantes de investigación: ¿Cuáles son las representaciones sociales de la discapacidad en la comunidad? ¿Qué paradigma se presenta en el discurso-acción de las representaciones sociales? ¿Cómo influyen las representaciones sociales en las acciones de la comunidad hacia las personas con discapacidad? ¿Cómo participa la comunidad en la inclusión de las personas con discapacidad?

\section{Investigación en discapacidad}

Como se ha mencionado, el tema de la discapacidad ha permeado en el interés tanto en la intervención profesional como en el campo de la investigación, dicho interés comienza a manifestarse en el siglo XIX con el término Disability en Inglaterra, término que fue ocupado para referirse a las personas que no podían realizar el servicio militar por su condición física, gestando así los pilares de diversos estudios de normalización desde las ciencias naturales y exactas con la finalidad de dar un orden social, de acuerdo con Jullian (2011) estas acciones dieron paso a generar la noción moderna de discapacidad.

Es así que, en los tiempos actuales el desarrollo de las ciencias generales y sus teorías, así como las especiales en discapacidad, según María López (2009), han permitido y motivado la aparición de nuevos enfoques en la concepción de lo que es la discapacidad y en las prácticas profesionales de investigación e intervención hacia las personas con discapacidad. Entonces, resulta necesario y fundamental enmarcar, desde la investigación, a la discapacidad en un referente teórico; que permita guiar las explicaciones de la realidad que se aborda.

Ante esto la discapacidad ha sido abordada desde las disciplinas y miradas médicas, psicológicas, históricas, educativas, económicas e inclusive artísticas, así mismo las disciplinas sociales han incursionado en los estudios e intervención hacia la discapacidad y las personas con discapacidad. Lo cual ha permitido tener datos ricos en análisis y reflexiones, que permiten a los futuros trabajos mirar y reivindicar las nuevas rutas o espacios que necesitan ser explorados, como lo son las representaciones sociales de las personas con discapacidad que se construyen en la vida comunitaria.

Sin embargo, las referencias que se tiene hacia la discapacidad, se han creado desde el pensamiento occidental, anglosajón primordialmente, que ha estructurado la explicación del mundo a partir de dicotomías, mediante el cual se van relacionando los diversos aspectos de la vida en sociedad. De esta manera sabemos lo que es bueno o malo, lo que es bello o feo, como menciona Shakespeare (1996) "las personas con discapacidad se definen como aquel grupo de personas cuyos cuerpos no funcionan, un aspecto diferente o actuar de manera diferente, que no puede hacer el trabajo productivo" (p. 96).

Por lo dicho anteriormente, las personas con discapacidad no están aisladas, pues sostienen una interacción con diversos actores como lo son la familia, las instituciones, los medios tecnológicos, los grupos de apoyo, organizaciones de la sociedad civil y la comunidad, donde se construyen representaciones, referencias, basadas en una condición que las ubica como seres estáticos y no dinámicos.

Es así que la comunidad, siendo el eje rector del presente estudio, es el principal medio de interacción y socialización de las personas con discapacidad, donde se crean las referencias de ellos y de la condición, pues en ellas se muestra las distintas formas de apoyo y comunicación hacia las personas con discapacidad y sus familiares.

Retomando los paradigmas
predominantes en la discapacidad,
médico y social, los cuales han aportado
al desarrollo teórico de la discapacidad y
a la visualización moderna de ésta, aún


se observan lagunas prácticas, pues en el contexto actual el mundo de las personas con discapacidad aún es un mundo de excluidos donde se sigue mirando a las personas con discapacidad como diferentes y estáticos, mirada que pareciera sigue legitimando el paradigma médico, pero que a su vez recurre al polo social donde se antepone la persona y no la condición, y que aún así se dificultad visualizar la persona de la condición.

Estas miradas e ideologías al ser vistas desde la mirada occidental, donde se refugia la dicotomía normal-anormal, es entonces que las personas sin discapacidad siguen influyendo, directa o indirectamente, en la dinámica de las personas con discapacidad, como menciona Moscovici (1981) en la influencia sucede algo que escapa a la conciencia del individuo: éste se comporta como si estuviera poseído por otro o pudiera poseer a otro y obligarle hacerle lo que no quiere.

En ese sentido, en la comunidad siendo un escenario inmediato de las personas con discapacidad, se van ubicando representaciones y acciones que influyen en el desarrollo de las personas con discapacidad en la vida comunitaria, y que así las representaciones y acciones van permitiendo la apertura u obstrucción a la inclusión social de las personas con y sin discapacidad en la vida comunitaria.

A partir de la apertura del campo de la discapacidad en las investigaciones, los esquemasconceptuales, las representaciones sociales que se tienen de la discapacidad, a decir de Brogna (2005) no están escritos en piedra, no son una fórmula inamovible, son conceptualizaciones cuestionables, criticables, movibles y re-definibles.

Moscovici (2011) refiere que el hombre cotidiano se vuelve el héroe involuntario de todas las maquinaciones teóricas, pues en los estudios se considera a un sujeto informante; es decir, los investigadores ubican a un sujeto que sólo proporciona datos a las interrogantes que se le hacen, sin embargo no se ubica a un sujeto pensante y consciente de la realidad en la que vive; por ello las representaciones sociales son construidas a partir de un sujeto que es consciente de la realidad en el que se desarrolla.

\section{La Discapacidad desde las Representaciones Sociales}

La teoría de las representaciones sociales surgió a partir del estudio realizado por Serge Moscovici en 1981, el psicoanálisis, su imagen y su público, sobre la difusión del psicoanálisis en la sociedad francesa.

En el caso del psicoanálisis, Moscovici hizo su estudio para ver cómo una teoría científica penetraba, se difundía dentro de la sociedad, tomaba ahí un objeto, digamos que podía estar al centro de conflictos intelectuales, o aún, políticos porque estábamos, en ese tiempo, en una situación de oposición entre dos mundos, el del Este y de los Estados Unidos. (Jodelet, 2003, p. 122)

El acercamiento que ofrece Denisse Jodelet, sobre la investigación de Moscovici, delinea que el psicoanálisis, en aquel momento histórico, se miraba como una teoría que venía de los Estados Unidos, por lo que dentro del público francés se tomaba una actitud de aceptación o de rechazo, hacia la teoría de Freud.

Por su parte el propio Moscovici, expuso "me propongo estudiar, por lo menos en parte, este hecho social mayor. El psicoanálisis está involucrado, puesto que me ha dado la oportunidad de examinarlo y ocupa un lugar central entre las corrientes intelectuales de nuestra época" (Moscovici, 1979, p. 13). Así entonces el estudio sobre las representaciones sociales del psicoanálisis, a decir de Lagache (1979), es una investigación de psicología social y sociología del conocimiento.

Ante lo ya descrito surge la pregunta ¿Qué son las representaciones sociales? Rodríguez (2001) explica que en los origines de la teoría, las representaciones sociales estaban referidas a la sociedad moderna. 
Por lo que su definición se vincula a transformaciones cotidianas de contenidos de la ciencia o, en el mejor de los casos, de elementos extraños y novedosos de la vida social que hacen circular los medios de comunicación.

Por lo que para Moscovici (1979) las Representaciones sociales son "un corpus organizado de conocimientos y una de las actividades psíquicas gracias a las cuales los hombres hacen inteligible la realidad física y social, se integran en un grupo o en una relación cotidiana de intercambios, liberan los poderes de su imaginación" (p. 18).

Es decir, las representaciones sociales son un constructo teórico, el cual se emplea para describir un estado mental o proceso social de cualquier naturaleza, a partir del cual se designan objetos físicos o ideales. Por lo que representar es sustituir, estar en lugar de, y por esta razón está empleada con el símbolo y con el signo. Así entonces la representación social no es una simple reproducción conceptual de algo o alguien, sino una construcción individual y/o colectiva que conlleva en la comunicación una parte de autonomía.

De acuerdo con lo anterior, una representación social es una forma particular del conocimiento de sentido común cuya finalidad es la elaboración de los comportamientos y la comunicación entre los individuos. Conlleva un carácter de significante que no solamente restituye de modo simbólico algo ausente, sino que puede sustituir loque está presente. Además, al aspecto de significante se le adhiere el aspecto de imagen. Ante este hecho la representación social aparece desdoblada en dos caras (Moscovici, 1979; Jodelet, 1986), la faz figurativa y la faz simbólica.

Resulta entonces que toda representación social se compone de figuras y expresiones socializadas. Es conjuntamente una organización de imágenes y de lenguaje, porque recorta y simboliza actos y situaciones que son o se convierten en comunes. Por lo que involucran no sólo el pensamiento verbal, racional, consciente, sino también elementos irracionales e inconscientes.

Así, las representaciones sociales producen los significados necesarios para comprender, actuaryorientarseen un medio social. Por esta razón, las representaciones sociales forman la identificación de la visión del mundo que los individuos o grupos llevan en sí y utilizan para actuar o tomar posición. Ante esto las representaciones sociales están sometidas a una doble lógica, (Abric, 2004), la lógica cognitiva y la lógica social, donde la coexistencia de ambas permite dar cuenta y comprender el por qué la representación integra a la vez lo racional y lo irracional.

Es el conocimiento social que Moscovici toma como el foco principal de la psicología social, disciplina donde se elabora la teoría de las representaciones sociales. Pues si bien los diferentes procesos cognitivos como la memoria, la percepción, la recopilación de información y la disonancia, trabajan juntos para proporcionar el conocimiento cognitivo real, éste se da dentro de un contexto social. Así pues, la teoría de las representaciones sociales entra en pugna con la teoría tradicional de cognición social, pues las representaciones sociales asocian lo subjetivo en la experiencia interna frente a lo objetivo del mundo externo.

La interrelacionado la subjetivo y objetivo se forma a través de la formación de una triangulación, Sujeto-Alter-Objeto, expresado en el modelo tríadico de la representaciones sociales que se enmarca en un contexto constructivista y dinámico (Valencia \& Elejabarrieta, 2007), pues se parte de la relación entre el conocedor y el objeto de conocimiento; es decir, la relación yo-objeto, la relación entre la cognición social (conocimiento socialmente compartido, ideología, creencias, etcétera) y un objeto de conocimiento social.

La teoría de la representación social reconoce el hecho de que el conocimiento es social en su origen y no el producto de la cognición individual. La relación epistémica de la persona con un objeto se define y es mediada por las otras personas relevantes. 
Es así que el grupo, a través de su sistema de representaciones elaborado en el discurso y en los actos de comunicación, es la base a partir de la cual el individuo comprende e interactúa con el mundo.

Dicha triangulación, así como el conocimiento social que ubica Moscovici, se va alimentando a partir del sentido común, elemento principal del cual se desglosan y construyen las representaciones sociales. Por esta razón, el sentido común recupera los conceptos, analogías y formas lógicas de la ciencia. Es un conocimiento producido en forma espontánea por los miembros de un grupo, basado en la tradición y el consenso, un conocimiento de primera mano que, en su caso, podría refinar la ciencia.

Ante esto, hay que entender al sentido común como un subproducto de la ciencia divulgada por los medios de comunicación y un producto de los intercambios comunicativos cotidianos. Por lo que caracteriza al sentido común no es sólo su oposición y/o subordinación a los contenidos de la ciencia o, en sentido amplio, a los diversos dominios expertos o especializados. Es decir, con el sentido común se vulgariza, por así decir, la ciencia en la cultura popular y la cual es vigilada por la cultura científica.

Las representaciones sociales al ser formuladas desde un sistema sociocognitivo se visualizan dos componentes:

Componente cognitivo: la representación supone lo hemos dicho, un sujeto activo, y tiene desde ese punto de vista una textura psicológica, sometida a las reglas que rige los procesos cognitivos. Componente social: la puesta en práctica de esos procesos cognitivos ésta determina por las condiciones sociales en que una representación se elabora o se transmite. Y esta dimensión social genera reglas que pueden ser muy distintas de la lógica cognitiva. (Abric, 2004, p. 13)

Ante este hecho, la coexistencia de ambas permite dar cuenta y comprender por qué la representación integra a la vez lo racional y lo irracional, es entonces a partir de esta composición cognitivosocial, que se desarrollan dos sistemas de contextualización, por ello que es el contexto social un elemento de suma importancia pues Jovchelovitch (2001), refiere que la unidad del contexto social es elemental para la construcción y análisis de las representaciones sociales, pues es la base para el entendimiento de las representaciones que se construyen $y$ reconstruyen en tiempos y espacios delimitados, que van formando el conocimiento social que marca Moscovici.

En suma, las representaciones sociales de la discapacidad en la vida comunitaria, recupera esta teoría como eje central de análisis, pues las personas con y sin discapacidad conocen la realidad que les rodea mediante explicaciones que extraen de los procesos de comunicación y del pensamiento, por lo que se sintetizan dichas explicaciones y en consecuencia hacen referencia a un tipo específico de conocimiento que juega un papel crucial sobre cómo la gente piensa y organiza su vida cotidiana.

De esta forma las representaciones de la discapacidad en la vida comunitaria, se conforma a partir del objeto de la discapacidad, pues se inserta en un contexto activo y móvil y su imagen y conceptualización es concebida por la colectividad; así entonces la discapacidad se interrelaciona con la comunidad el cual se convierte en el sujeto, dicha interrelación se ve analizada y medida por las personas con discapacidad $(\mathrm{PcD})$ el cual forma el alter. Por lo que esta triada va delineando las representaciones de la discapacidad.

Por tanto, ubicar los elementos como la inclusión, exclusión, de influencia y de conceptualización de las personas con discapacidad en la dinámica comunitaria, se reflejan en las aportaciones de actitud y narrativas de las personas que habitan en la comunidad, que van creando representaciones sociales, ya que Moscovici 
(1979) ubica éstas representaciones sociales como entidades casi tangibles que circulan, se cruzan y se cristalizan sin cesar en nuestro universo cotidiano a través de una palabra, un gesto, un encuentro.

\section{Metodología de Investigación en las Representaciones Sociales de la Discapacidad}

De acuerdo con Díaz (2010) el conocimiento es una forma de relacionarse con la realidad, un modo de interpretarla y de dar cuenta de ella, por lo que el conocimiento describe, explica y predice; así pues, ente sentido la investigación se desarrollo bajo el nivel descriptivo.

El estudio al ser un trabajo que abordó datos desde la mirada cuantitativa y cualitativa, se optó por el enfoque denominado integración de métodos, de acuerdocon Manuel Bericat (1998) el mundo natural se explica, mientras que el mundo social se comprende, por ello que cada vez es más evidente que la separación del método cuantitativo y cuantitativo, limitan seriamente la posibilidad de la ciencia para alcanzar descripciones o cuantificaciones, compresiones o explicaciones, criticas o legitimaciones, validadas, precisas y fiables de la realidad social.

Por ello que la integración de métodos permitió al estudio analizar las representaciones sociales de la discapacidad desde una mirada integral, confrontando datos numéricos y narrativos que se obtuvieron de la participación de los habitantes de la comunidad y de las personas con discapacidad, creando así datos que permitan conjugar la teoríapractica del tema a investigar.

Ahora bien, esta integración de métodos, se guio bajo la estrategia metodológica de triangulación donde:

Se trata de utilizar ambas orientaciones para el reconocimiento de un mismo e idéntico aspecto de la realidad social. Los métodos son implementados de forma independiente, pero se enfocan hacia una misma parcela de la realidad que quiere ser observada o medida con dos instrumentos diferentes. En la triangulación por tanto el grado de integración aumenta. (Bericat, 1998, p. 37)

Se ha descrito el enfoque y la estrategia metodológica que se optaron en el presenteestudio, dondedicha integración de métodos ayudará a obtener datos reales, profundos y sólidos para el estudio, sin embargo ante el hecho de integrar métodos Bericat (1998) invita a realizar un deconstrucción de los dos grandes métodos existentes, cuantitativo y cualitativo, para queasí se puede consolidar uno solo, por ello que la deconstrucción realizada encamino a conocer la aproximación monográfica de las representaciones creadas de la discapacidad en la vida comunitaria.

Dicha aproximación monográfica, según Abric (2004) es un proceso mucho más ambicioso, lento y difícil de ejecutar, sin embargo, cuando es realizable, es la vía regia del estudio de las representaciones sociales. Así pues lo que refiere la aproximación monográfica está articulada por: A) el análisis contextual, construida desde elementos etnográficos, es el espacio que permitió conocer más a profundidad el área geográfico-social donde se desarrolló la investigación, es decir la descripción de la comunidad, B) el acercamiento cuantitativo es el momento que formó el conocimiento estadístico de las representaciones sociales de la discapacidad, a partir de un cuestionario, C) el acercamiento cualitativo se desarrolló por medio de la entrevista semi-estructurada, permitiendo conocer el discurso del Alter, es decir accedió al conocimiento de la realidad real de la discapacidad a través de la persona que lovive día a día y $\mathrm{D}$ ) análisis triangular que permite conocer el campo de la representación social, el cual es uno de los componentes de las representaciones sociales.

\section{Representaciones sociales de la discapacidad en la comunidad \\ Es momento de descubrir cuál es}


el paradigma de la discapacidad que se encuentra debajo del "disfraz social" y así cuestionar la representación social que se piensa, se habla y se actúa sobre la discapacidad en la vida comunitaria.

Por ello se inicia por conocer la comunidad que fue escenario de la investigación, vislumbrando así el contexto en el que se desarrollan las representaciones sociales en la que se desenvuelve la condición de la discapacidad. Y es que considerando lo expresado por Blau (1977) la estructura social marca al sujeto a través de las diferencias sociales que se desarrollan a través de roles y asociaciones; entonces la comunidad al ser delineado como la estructura social de las representaciones sociales de la discapacidad, es que los habitantes con y sin discapacidad, a través de su estructura social mediata, su comunidad, se capacitan para convertirse en aquellas personas conscientes de su realidad y así actuar en ella.

Por eso que conocer la estructura social de las Representaciones creadas, verdades falsas, de la discapacidad en la vida comunitaria, no solo dejara visualizar la composición de dicha estructura, de la comunidad, sino que además forma el contexto social que marca Jovchelovitch (2001) como fuente principal del conocimiento social para la construcción y análisis de las representaciones sociales.

En lo que refiere a la dimisión geográfica, la comunidad sede del estudio, se localiza en el municipio de Ecatepec de Morelos el cual forma parte de los 120 municipios situados en el Estado de México, el municipio se integra por: 1 Ciudad, 8 Pueblos, 6 Ejidos, 12 Barrios, 163 Fraccionamientos y 359 Colonias.

Dentro de las 359 Colonias se encuentra la Colonia Gustavo Díaz Ordaz, localizada al sur del municipio la cual fue sede de la investigación; la Colonia Gustavo Díaz Ordaz se clasifica como una comunidad urbana, la colonia cuenta con una delimitación geográfica trazada por 8 calles y 3 avenidas, que albergan 16 manzanas en total, en la que se distribuyen 446 lotes en total de los cuales 430 se encuentran habitados.

Resultó interesante conocer el espacio comunitario sede de la investigación, ya que se observó una solides institucional y de infraestructura, como también una dinámica que muestra una convivencia recíproca entre los habitantes. Es por ello que la comunidad Gustavo Díaz Ordaz, figura como la estructura social en la que sus habitantes y procesos sociales, se interrelaciona con los sucesos sociales, políticos y culturales que ocurren a nivel municipal, estatal o federal, por ello que la estructura social de la comunidad resulta ser cambiante.

Pues sus cara social, cultural, política y económica, forman canales de relaciones entre los sujetos-sujetos y objetos-sujetos, que a través de las diferencias culturales dentro de la misma estructura social, comunidad, se organiza toda una serie de información sobre sus habitantes y contexto, que van marcando una realidad socio-cultural, que es atravesada por emociones y conductas que formulan un sentido común sobre el otro que se ve y que se describe, llevando así a una apropiación de lo nuevo.

La vida cotidiana, siendo la segunda esfera donde se forma la representación social, es el espacio en el que se ancla lo subjetivo y objetivo de la representación creada de la discapacidad en la vida comunitaria; por lo que de acuerdo con González (2007) para conocer la resolución objetiva de una persona, hay que preguntar de forma cerrada, mientras cuando se cuestiona de forma abierta, es decir que la persona no esté sujeta a una determinada repuesta, esta expresa su sentir subjetivo, ante ello visualiza los elementos cuantitativo y cualitativo, a través de lo comúnmente llamado como preguntas abiertas y cerradas.

La comunidad al contar con un total de 430 lotes habitados, este total fue la población total a entrevistar a través del 
cuestionario, sin embargo, solo el $76.74 \%$ acepto participar, mientras que el $11.63 \%$ no acepto participar y otro $11.63 \%$ no se encontraban personas que pudieran contestar el instrumento

Del total de la población participante, 330 personas, el $59.70 \%$ son mujeres mientras que el $40.30 \%$ son hombres, en los cuales el rengo de edad: 39 a 45 años obtuvo mayor frecuencia con un 20.91\%; al ser más mujeres que participaron en la investigación se obtuvo que la ocupación principal es el hogar con un $56.67 \%$, mientras que le sigue con un $13.64 \%$ el ser comerciante, por esta razón se podría decir que de acuerdo a la cantidad de negocios formales e informales dentro de la comunidad, son la fuente principal de ingresos de las familias de la comunidad.

Habiendo conocido el perfil de la población participante, se da inicio a marcar las dimensiones de información y actitud; por lo que la segunda sección del instrumento albergó la dimensión sobre la información, así como percepción, que tiene de la comunidad sobre la condición de la discapacidad.

Así pues, el $70.61 \%$ indico que si ha visto o escuchado el termino discapacidad, mientras que el $39.39 \%$ no lo ha visto o escuchado, los medios de comunicación como: la televisión y la publicidad son la principal fuente de quienes han visto o escuchado el terminado discapacidad, esto con un $26.32 \%$ y $21.93 \%$ respetivamente, mientras que la radio o prensa son medios secundarios, es interesante observar que otros medios como los personales o institucionales sirven como espacios de difusión del término discapacidad, lo cual deja saber que al hablar de discapacidad es hablar de un tema conocido socialmente.

$\mathrm{Al}$ mencionarle a la población entrevistada, que refiera cuatro palabras que asocie al término discapacidad, la palabra con mayor frecuencia fue invalido con un $16.67 \%$, mientras que limitación con un $11.36 \%$. Ante esto es que la discapacidad desde el sentido común se visualiza desde un constructo médico, ya que las principales palabras, reflejan la dicotomía de discapacidad-enfermedad. Sin embargo, es atrayente que el $7.58 \%$ de los entrevistados lo asocien con una persona.

El tipo de discapacidad más conocido por la población, con mayor frecuencia es la discapacidad física, esto posiblemente por la razón de que es la discapacidad que tiene mayor visibilidad sea a nivel social o a través de los medios de comunicación quienes son la principal fuente de información. La principal causa de la discapacidad, de acuerdo a la comunidad, está relacionada con problemas durante el embarazo $25.27 \%$, mientras que la enfermedad es la siguiente causa $24.24 \%$, el $3.03 \%$ de la población no sabe la cusa.

Dentro de la información que tiene la comunidad hacia la discapacidad, la cual también se obtiene a partir de la experiencia, es que el $79.91 \%$ La población entrevistada indica que si conoce personas con discapacidad, de este total el $75.45 \%$ ha tratado a un persona con discapacidad, ahora bien si es cierto que la mayoría de la población ha conocido y tratado a personas con discapacidad; para el $47.88 \%$ de la población total entrevistada le es: ni fácil ni difícil relacionarse con una persona con discapacidad, por lo que para el $30.30 \%$ de la población le es fácil relacionarse y el $21.82 \%$ le es difícil.

Al recordar los tres principales enfoques en los que se ha desarrollado la discapacidady la persona con discapacidad (social, médicorehabilitador y prescindencia) y los cuales han construido la imagen de la persona con discapacidad de acuerdo al contexto, es que para el 78.79\% de la comunidad Gustavo Díaz Ordaz, la persona con discapacidad es una persona con derechos, mientras que para el $12.12 \%$ es un enfermo y el $9.09 \%$ indica que es un pobre.

Si bien es cierto que se observa la construcción social de la persona con discapacidad, al indicar que es una persona con derecho y posicionándola así desde el modelo social de la discapacidad, resulta que:

Al estar entrevistando a una 
participante y preguntar sobre si la personas con discapacidad es un enfermo, un pobre o una persona con derechos, menciona que es una persona con derecho, pero que no todos piensan así pues su vecina, quien tiene un nieto con discapacidad lo niega "pues según ella dice que es del dominio, que embrujaron a su hija y así salió su nieto, trata bien feo a su nieto y a su hija también, pues la muchacha luego viene aquí y me dice que su mamá no la ayuda en nada y que ya le dijo que tire a su hijo a la calle, que porque por su culpa su casa está casi embrujada. (Diario de campo)

Resulta pues, que la ideología místico-religioso, aún persiste y que lleva así a mostrar actos de prescindencia. Por lo que si bien es un único caso que se presentó en la comunidad, no deja de ser transcendental el impacto que tiene dicha imagen/actitud.

Ahora bien, entender la actitud remite conocer el contexto social, el cual se ha hecho en la sección anterior, pero además recurre a conocer de forma objetiva el posicionamiento de la actitud del sujeto frente a algo, en este caso la actitud frente a la discapacidad, pues de acuerdo a Gorge Gaskell (2001) es la conjugación del contexto social y la cognición individual.

Por lo que una actitud es considerada como un estado disposicional, como una respuesta emotiva o como una tendencia a comportarse positivamente o negativamente; así que para conocer la actitud hacia la discapacidad-persona con discapacidad, se desarrolló una escala, la cual cubrió la disposición hacia: A) la condición de discapacidad, B) el desarrollo humano de la persona con discapacidad, C) la exclusión de la persona con discapacidad, D) la relación sociedad-persona con discapacidad y F) el desarrollo social de la persona con discapacidad.

De acuerdo a lo obtenido en la suma total de putos de la escala aplicada a la población, se observa que tiene una disposición de actitud positiva hacia la discapacidad-persona con discapacidad, pues el rango con mayor impacto es el de 30 a 50 puntos, por lo que dentro de este rango el puntaje de 43 y 50 puntos tuvieron mayor frecuencia con un $16.67 \%$ y $17.88 \%$ respectivamente.

Esta actitud positiva que muestra la población, impacta en la práctica social hacia la discapacidad-persona con discapacidad, ya que del total de la población entrevistada el 90\% indica que si apoya a las personas con discapacidad cuando las ve, mientras que el $10 \%$ no las apoya.

Por lo que respecta a la presencia de las personas con discapacidad en la comunidad Gustavo Díaz Ordaz, el 53.03\% de la población entrevistada indica que ha visto a personas con discapacidad, mientras que el $46.97 \%$ no ha visto a personas con discapacidad en la comunidad.

Al ser más vistas a las personas con discapacidad en la calle o negocios, es que el $63.64 \%$ de la comunidad reconoce a las personas con discapacidad como vecino, mientras que el $15.15 \%$ como amigo y el $12.12 \%$ ninguno, sin embargo, el $9.09 \%$ son familiares. Por lo que las personas con discapacidad, tendrían un respaldo social de parte de su comunidad, ante esto según el $70.0 \%$ indica que la condición de la discapacidad no limita su desarrollo en la comunidad, mientras el $30.00 \%$ de los entrevistado indica que la discapacidad si limite a la persona en la comunidad.

El aspecto de los derechos es de las razones por la que la discapacidad no limita el desarrollo de las personas con discapacidad en la vida comunitaria, pues el $42.86 \%$ indica que tanto las personas con y sin discapacidad tienen los mismos derechos, por otra parte, el 33.77\% indica que son iguales, mientras que la inaccesibilidad de la comunidad, es una de los motivos por las que la discapacidad si limita el desarrollo de las personas en la comunidad.

Resulta interesante que el $35.00 \%$ de 
la población indica la falta atención hacia las personas con discapacidad; ante esto el $72.73 \%$ de la población total indica que tanto la familia, gobierno, profesionales, vecinos y amigos serían las personas que tendrían que atender a las personas con discapacidad, mientras que el $18.18 \%$ indican que tendría que ser únicamente la familia, el $6.06 \%$ exclusivamente el gobierno y 3.03\% sólo los profesionistas.

En definitiva, los datos obtenidos desde la observación hasta el cuestionario, envuelven una serie de argumentos y actos ricos a ser reflexionados. Llevando así a entender que todo hombre y mujer al nacer se encuentra en un mundo ya existente, independiente de él o ella, pues este mundo se le presenta ya constituido y aquí él o ella debe conservarse y dar prueba de su capacidad vital, según Heller (2012).

Es entonces que, dentro de dicha cotidianidad constituida, no solo cabe la voz de unos, en este caso de las personas sin discapacidad, sino que también es vital la palabra/voz de las personas con discapacidad, llevando así a la construcción y reconstrucción, a partir de lo vivido y la experiencia, de las representaciones sociales de la discapacidad.

Lo anterior recupera la interrelación tríadica comunidad-discapacidad-persona con discapacidad, que configura todo un dialogo entre sujeto-sujeto, comunidadpersonas con discapacidad, objeto-sujetos, discapacidad-comunidad/personas con discapacidad. Dejando ver así la creación de representaciones falsas o verdaderas sobre la discapacidad desde quien la ve y quien la vive.

Así entonces, de acuerdo a lo obtenido durante la fase de aplicación del cuestionario se reconoció un total de 13 personas con discapacidad en la comunidad, de las cuales solo 8 aceptaron participar en entrevistas semi-estructuradas. La población con discapacidad que participo en la investigación es 50\% hombres y 50\% mujeres; la comunidad menciono que la discapacidad física es la más conocido, ante este hecho es que dicho tipo de discapacidad es quien tiene mayor incidencia en la población con discapacidad entrevistada, mientras la intelectual y visual le siguen con dos casos respectivamente, la mayoría de las personas entrevistada adquirieron la discapacidad por causa de enfermedad, accidente y durante el nacimiento, la etapa en la que se encuentran las personas con discapacidad es adulta.

Así entonces, desde la palabra/voz las personas con discapacidad, de acuerdo con Montobbio (1995), aportan una contribución a la fecundidad cultural del mundo que es una prerrogativa de todos y cada uno, pero esta contribución sólo puede darse ante una construcción aceptable del Yo, ante un acceso suficientemente consiente a la dimensión de Yo soy.

Ante esto, para 3 personas, la discapacidad es una enfermedad, para 4 es una limitante, mientras que para una es la falta de una parte de su cuerpo. Así entonces que la discapacidad, tanto para las personas con y sin discapacidad es vista desde la salud-enfermedad, quizá resultado del factor escolaridad, pero también desde la concepción propia de enfermedad, al entender esta como una alteración del estado "normal" de la salud; se observó que el termino discapacidad es visto o escuchado principalmente desde los medios de comunicación, por lo que las personas con discapacidad indica que la información acerca de la discapacidad que dan dichos medios es cierto, pero:

$\mathrm{Si}$ se pasan luego con lo que es la discapacidad, el otro día estaba escuchando en la radio que los niños que son síndrome de Down son angelitos y eso no es cierto, lo cierto es que hay un cromosoma mal y que es un niño como todos, sino imagínate los demás niños serian diablos, pues todos son angelitos cuando se portan bien y son diablos cuando se portan mal". (Entrevista semiestructurada, $\mathrm{PcD}_{5}$ )

Es decir, a pesar de que los medios de comunicación dotan de información 
"real" sobre lo que es la discapacidad y las personas con discapacidad, pareciera que aún se sigue con los sentimientos de "bueno o malo" hacia la discapacidad/persona con discapacidad, desarrollando actitudes basados en los mitos mass-media, mitos de los medios de comunicación. Mircea Eliade (1994) expresa que las huellas de dicho comportamiento mitológico vislumbran la intensidad que se ha vivido, o conocido, una cosa por primera vez; por ello desde quien vive la discapacidad no existe una novedad emocional sobre la condición y rechazan el sentimentalismo que hay sobre la discapacidad/persona con discapacidad.

Al develar la voz de las personas con discapacidad y conjugarse con la voz de la comunidad, es que se activa el elemento de la subjetividad, pues si bien es cierto que se a anclado y objetivizado el sentido común sobre discapacidad/persona con discapacidad a partir de las características biológicas y orgánicas, es que se suman significados, los cuales se expresan en códigos y subcódigos que explican, justifican y reiteran la diferencia, así como la discapacidad, de acuerdo con Zardel Jacobo (2008).

Así que, dichos códigos y subcódigos se traducen en las formas mirar y actuar sobre la discapacidad/personas con discapacidad, que se van consensando por la comunidad y las mismas personas con discapacidad; por lo que, en razón de esto, se ha visto que la comunidad reconoce a la persona con discapacidad, como una persona con derechos, ante esto las mismas personas con discapacidad se posicionan como personas con derechos.

Si tengo derechosy soy una persona que tiene derecho como todos a la salud, a tener seguridad, empleo y también derecho a divertirme. (Entrevista semi-estructurada, $\mathrm{PcD}_{5}$ )

Pus si tienen derechos como todos, aunque ellos a los mejor no lo saben, pero si los tienen y la gente los ayuda a reclamarlos, por ejemplo hace ya como tres años vino un candidato del PRI y pues el delegado de la comunidad en ese entonces le exigió que los apoyaran porque son personas que tiene derechos como todos. (Entrevista semi-estructurada PcD6 y $\left.\mathrm{PcD}_{7}\right)$

$\mathrm{Si}$ soy una persona que tiene derechos, por eso luego voy a la delegación y voto o me peleo con las personas por tener una mejor colonia, me gusta mucho participar a favor de la colonia y pues así también les muestro a los jóvenes que no por mi edad y mi discapacidad no tengo derechos a decidir. (Entrevista semiestructurada, PcD8)

Así entonces el código de la discapacidad, que se hace tangible a través de la imagen corporal, y los subcódigos que se establecen a partir de la forma de actuar o ser de las personas con discapacidad, es como se construyen las significaciones que gestan la identidad del grupo social $\mathrm{y}$ permiten en los tiempos rutinarios y cotidianos, la visibilidad real y consiente de la discapacidad/persona con discapacidad.

Por lo que ante esta realidad de que las personas con discapacidad son personas activas, y no meras receptoras de apoyos, es que los discursos entre comunidadpersonas con discapacidad, justifican el sentir y pensar, el cual ya se ha visto, de la comunidad frente a la discapacidad.

Ahora bien, al desarrollar las entrevistas con las personas con discapacidad, al igual quecon la comunidad, es importante entender la actitud que se tiene sobre la condición, ya que el conocer dicha actitud remite a desmembrar la dimensión emotiva del sujeto, de la cual habla Jordi Planella (2006), donde las emociones y sentimientos de cada persona con o sin discapacidad, dan sentido a la experiencia humana.

Tanto profesionales del campo de la investigación, así como personas con discapacidad han expresado la creencia 
que se tiene sobre los sentimientos y/o emociones de las personas con discapacidad, al indicar que dentro de la vox populi se cree que no tienen ni uno y ni otro, creando así unas personas sin gracia, llevándola a la tragedia que sucede al tener la discapacidad.

Sin embargo las personas con discapacidad de la comunidad Gustavo Díaz Ordaz, al hablar de su actitud frente a la condición, se observó que al adquirir su discapacidad mostraron un sisma dentro de su ser, ya que sabían que al tener la discapacidad cambiarían hábitos e inclusive sentimientos, sin embargo se fueron disponiendo a una realidad cambiante de su cuerpo, más no de su forma de acción en su cotidianidad, la discapacidad es una condición que les permite enseñarles a los demás, pero sobre todo a ellos mismos de que pueden desarrollarse al igual que una persona sin discapacidad.

Ante este hecho, quizá, es que la comunidad expresa tener una admiración por las personas con discapacidad, pues les muestran el sentir de la vida a través de los esfuerzos que estos le dan a la cotidianidad en la comunidad, así que su condición real como personas que manifiestan a través de la actitud positiva frente a su condición, es que se traduce un espacio emocional favorable, generando así la construcción de un puente entre la discapacidad y la acción social de la comunidad y las personas con discapacidad.

De acuerdo con Spadillero (2009), la comunidad gesta un orden que determina el lugar de los otros, en el cual las personas con discapacidad en la vida comunitaria, se enfrentan a barreras físicas, sociales y/o culturales, a partir de los esquemas urbanos en los que se encuentra inserto.

Ante este hecho es que las personas con discapacidad, al menos las entrevistas, a partir de su expresión verbal, es que van construyendo una cultura de la discapacidad, en la comunidad como estructura social. Pero son la propias personas con discapacidad que dan muestra de la capacidad proactiva hacia el accionar en la vida comunitaria, ejemplo de ello es la PcD8 quien en relatos anteriores indica que va a la delegación a "pelarse" o votar a favor de su colonia, pero también revelan, tanto de forma consiente como inconsciente, una acción de sensibilización sobre su condición en la comunidad, como bien lo llega a hacer la $\mathrm{PcD}_{5}$ al indicar que desde su condición de personas con discapacidad, trata de enseñarles a sus vecinos su capacidad desde su sentir como persona y no desde la condición.

\section{Discusión}

Descubrir y analizar el paradigma de la discapacidad que se encuentra debajo de aquel “disfraz social” y, así, poder cuestionar la representación social que se piensa, se habla y se actúa sobre la discapacidad en la vida comunitaria; resulta ser un ejercicio sumamente interesante que se convierte en un acto no solo atractivo, sino también un tanto difícil de recuperar, puesto que implica atender dos aristas que configuran las respuestas a saber sobre dichas representaciones sociales.

Estas dos aristas son: A) desmembrar todo una serie de diálogos que se han legitimado sobre lo que es y no es la discapacidad y B) elaborar nuevos esquemas de argumentos que dejen ver el rostro real de la discapacidad; y es que la representación social resulta ser aquel proceso que implica la reconstrucción del conocimiento que es compartido socialmente, así como su creación e innovación en la actividad humana; por lo cual se va traduciendo en una co-construcción entre el yo conocedor y el otro.

Así pues, que comienza el acto de saber que son las representaciones creadas, verdades falsas, de la discapacidad en la vida comunitaria; en la sección anterior se pudo apreciar ya todo lo referente al trabajo de campo que deja a luz, un trabajo que permite ver a las personas con y sin discapacidad, como participantes activos de una red y un contexto social de naturaleza variada, llamada comunidad Gustavo Díaz Ordaz. 
Y es que, al compartir dicho contexto variado deja ver en claro el retorno de aquel sujeto consciente de la realidad, donde personas con y sin discapacidad van construyendo un ordenamiento sociocultural, el cual según Jacinto Choza (2012), resulta ser un escenario para la representación propia y un conjunto de procedimientos para actuar, para componer la figura, para ser uno mismo y para mentir.

Resulta motivador y complejo a la vez lo que expresa Choza, pero al delinear el campo de la representación social, es necesario delinear, o al menos hacer el esfuerzo, de conocer aquel sujeto sea con o sin discapacidad desde una mirada filosófica; así entonces al plantarse la pregunta: ¿Qué se cree de la discapacidad?, resultar ser una pregunta muy atrevida, pues se puede creer mucho y nada sobre una condición que parecería que no existe para algunos, mientras que para otros es lo mismo lo ayer que lo de hoy; por ello que resulta primordial marcar la importancia de los conceptos, como bien lo explica Mauricio Mereño (2012) hay que problematizar el sentido común de una condición que se ha visto solo desde la medicina o desde los medios de comunicación.

Así que ¿Para quién es discapacidad? y ¿De quién es la discapacidad?, ante este hecho la discapacidad para la comunidad Gustavo Díaz Ordaz, al igual que para las personas con discapacidad de la misma, se van desarrollando desde el elemento del lenguaje, donde cada uno a partir de su voz/palabra dejan de ser ellos mismos, comenzando a ser identificados a través de las representaciones y papeles, donde pueden llegar a ser triunfadores, un ejemplo o un arquetipo.

Bien se puede observar en los relatos de las personas con discapacidad, donde muestran, o dejan ver, una persona que al igual que todos tiene emociones, sentimientos, habilidades, visiones, metas y es un fiel sensibilizador permanente, sin llegar a considerarse un triunfador o un ejemplo, simplemente son un ciudadano; pero en el discurso de la comunidad se activa en un juego paradigmático, es decir el paradigma que se presenta en el discursoacción, se penetra en una diada médicosocial, pues para la comunidad le resulta equivalente la discapacidad a enfermedad o la carencia de algo sea la función de o la perdida de algún miembro del cuerpo, mientras que a la vez le resulta que la persona tiene derechos y así mostrar una actitud positiva frente a la discapacidad/ persona con discapacidad.

Es cierto que el lenguaje se encuentra en la base de casi toda nuestra experiencia, dejando ver los afectos, emociones, imaginación, encuentros y desencuentros, creencias, decisiones, elecciones, preferencia, por lo que prácticamente toda conducta se nutre y realiza en y a través de este humus omnipresente en la actividad humana. Donde aprendamos a nombrar a las cosas y a las personas a partir de nuestro entorno; pero también al mismo tiempo, integramos prejuicios, matices despectivos, atribuciones arbitrarias.

Por ello que de pronto el leguaje de la discriminación se alimenta de la carne y la sangre de personas puestas históricamente en situación de vulnerabilidad, como lo son las personas con discapacidad, sin embargo, de acuerdo con Hugo Islas (2005) nuestra cultura está traspasada por hábitos lingüísticos que son a menudo vejatorios y ofensivos para quienes difieren en algún aspecto de la mayoría.

Así que desde las palabras podemos ir ascendiendo en complejidad lingüística hasta llegar a las creencias, teorías y grandes narrativas que, en su calidad de instrumentos discursivos, son capaces de minusvalorar y hasta borrar a conjuntos humanos complejos. Por lo que hablar de la discapacidad desde el otro, como lo fue la comunidad/personas con discapacidad.

Para ello, la visión de Foucault (1968) permite entender el sinfín de "molestias" de nombrar al otro, pues al expresar que es en el siglo XIX que la normalización gestada desde la medicina, instalo los modos de regulación de las relaciones, experiencias cotidianas (con sus expectativas, ilusiones 
y esperanzas), estando así las personas con discapacidad sometidos a la regulación deseable el del cuerpo "sano y bello".

Se ha indicado, que la construcción de la discapacidad se ha elaborado desde el pensamiento del occidente, lo que seguramente esto genera que sea un tanto confuso la explicación de la discapacidad y las personas con discapacidad en los contextos Latinoamericanos, por lo que resulta importante entender el pensamiento occidental.

Ante ello Foucault, centra el pensamiento occidental en el concepto de épiméleia/cura sui, este concepto equivale, según Foucault (1968), a una actitud general, es decir a un determinado modo de enfrentarse al mundo, a un determinado modo de comportarse, de establecer relaciones con los otros. Lo que implica una actitud en relación con uno mismo, con los otros y con el mundo.

Por loquesevislumbra una autonomía en el habla, en la medida en que existe, está condicionada por una dependencia radical $\mathrm{y}$ originaria del lenguaje, un lenguaje cuya historicidad excede en todas direcciones de la historia del sujeto hablante. Y esta historicidad excesiva, hace posible tanto la supervivencia lingüística del sujeto como su muerte.

\section{Conclusión}

En suma, entender aquella "tragedia de la discapacidad" de lo que es verdadero o falso, es entenderlo desde el aquí y ahora, desde el estado subjetivo contemporáneo de la discapacidad, por lo que la comunidad Gustavo Díaz Ordaz, su habitantes y las personas con discapacidad, hoy construyen un estado humanista de la discapacidad, en virtud de que a parir de su voz/palabra no defiende a una persona extraña o diferente, sino defiende los derechos de las personas ordinarias y el conocimiento tradicional ante los embates y engaños a los que han estado subordinados, como bien lo expresa Moscovici (2011).

Sin lugar a duda, analizar la representación social de la discapacidad en la vida comunitaria resulto ser complejo, pero sobretodo fue un ejercicio atractivo y estimulante, pues quizá hoy, con este estudio se rompe una tradición en la forma de entender no a una persona y una sociedad excluyente, sino un campo que resulta ser infinito la Discapacidad, pero a la vez también se muestra el alcance que tiene la forma de investigar desde Trabajo Social.

\section{Referencias Bibliográficas}

Abric, J. (2004). Prácticas sociales y representaciones. México: Ediciones Coyoacan.

Bericat, M. (1998). La integración de métodos cuantitativos y cualitativos en la investigación social. Significado y medida. Barcelona: Ariel Sociología.

Blau, P. (1977). A mracrosociological theory of social structure. The American Journal of Sociology, 83(1), 26-54.

Brogna, P. (2005). El nuevo paradigma de la discapacidad y el rol de los profesionales, de la rehabilitación. Buenos Aires: Ed. Cisne.

Choza, J. (2012). Antropología filosófica, las representaciones del sí mismo. Madrid: Biblioteca nueva.

Díaz, E. (2010). Metodología de las ciencias sociales., Buenos Aires: Biblos.

Eliade, M. (1994). Mito y realidad. Bogotá: Quinto escenario.

Foucault, M. (1968). Las palabras y las cosas. Buenos Aires: Siglo XXl.

Gaskell, G. (2001). Attitudes, social, representations, and beyond. En K. Deaux, \& G. Philogéne (Eds.), Representations of the social. Bridging theoretical Traditions (pp. 165-182). London: Blackwell.

González, F. (2007). Investigación cualitativa y subjetividad, los procesos de construcción de la información, India: McGraw-Hill.

Heller, Á. (2002). Sociología de la vida cotidiana. Madrid: Ediciones Península. 
Islas, H. (2005). Lenguaje y discriminación. México: CONAPRED.

Jacobo, Z. (2008). Discapacidad y subjetividad. Revista Latinoamericana de Estudios Educativos, 38(3-4), 233244.

Jodelet, D. (1986) La representación social: fenómenos, concepto y teoría En S. Moscovici (Ed.), Psicología social (Tomo II, pp. 469-494). Barcelona: Paidós.

Jodelet, D. (2003). Entrevista a Denise Jodelet. Relaciones 93, 21(2), 117-132.

Jovchelovitch, S. (2001). Social representantions, public life, and social construction. En K. Deaux, \& G. Philogéne (Eds.), Representations of the social. Bridging theoretical traditions (pp. 165-182). London: Blackwell.

Jullian, C. (Ed.) (2011). Antología cursotaller: Modelos teóricos sobre discapacidad, revisión histórica y su aplicación práctica. México: Facultad de Filosofía y Letras-UNAM.

Langache, D. (1979). Prefacio. En S. Moscovici, El Psicoanálisis, su imagen y su público (pp. 5-10). Buenos Aires: Ed. Huemul.

López, M. (2009). Modelos teóricos $e$ investigación en el ámbito de la discapacidad. Hacia la incorporación de la experiencia personal. Córdoba, España: Universidad de Córdoba.

Mereño, M. (2012). El saber convencional sobre la discapacidad y sus implicaciones en la práctica. En $\mathrm{M}$. Alfonsina, \& M. Eugenia (Eds.), Debates y perspectivas en torno a la discapacidad en América Latina (p.p. 133-168). Paraná: UNER-Facultad de Trabajo Social.
Montobbio, E. (Ed.) (1995). La identidad difícil, el falso yo en la persona con discapacidad psíquica. Madrid: Masson.

Moscovici, S. (1979). El Psicoanálisis, su imagen y su público. Buenos Aires: Ed. Huemul.

Moscovici, S. (1981). Psicología de las minorías activas. Madrid: Ediciones Morata.

Moscovici, S. (2011). Prólogo. En W. Wagner, \& N. Hayes, El discurso de los cotidiano y el sentido común. La teoría de las representaciones sociales (pp. ix-xxxiv). España: Anthropos.

Planella, J. (2006). Subjetividad, disidencia y discapacidad. Prácticas de acompañamiento social. Madrid: ONCE.

Rodríguez, T. (2001). Las razones del matrimonio Representaciones, relatos de vida y sociedad. Guadalajara: CUCSH-UAG.

Shakespeare, T. (1996). Disability, identity and difference. En B. Colin, \& M. Geof (Eds..), Exploring the Divide (pp. 94113). Londres: The Disability Press.

Spadillero, A. (2009). La producción social de la discapacidad en las diferentes dimisiones de lo barrial. En A. Rosato (Ed.), Discapacidad e idolología de la normalidad (pp. 77-91). Buenos Aires: Ed. Noveduc.

Valencia, J., \& Elejabarrieta, F. (2007). Aportes sobre la explicación y el enfoque de las representaciones sociales En T. Rodríguez \& M. García (Eds.), Representaciones sociales. Teoría e investigación (pp. 89-136). Guadalajara: CUCSH-UAG.

\section{Sobre el Autor}

Tomás Silva Montealegre

Maestro en Trabajo Social, Escuela Nacional de Trabajo Social de la Universidad Nacional Autónoma de México. 